\title{
Nuplazid suppresses esophageal squamous cell carcinoma growth in vitro and in vivo by targeting PAK4
}

\author{
Yaxing Wei ${ }^{1,6}$, Wenjie Wu ${ }^{1,2,6}$, Yanan Jiang ${ }^{1,2,3,4,6}$, Hao Zhou ${ }^{1}$, Yin $\mathrm{Yu}^{1,2}$, Lili Zhao ${ }^{1,2}$, Xiangyu Wu ${ }^{1}$, Xuebo Lu ${ }^{1,2}$, Qiang Yuan ${ }^{1,2}$, \\ Zitong Wang ${ }^{1}$, Zigang Dong ${ }^{1,2,4,5}$, Luyun $\mathrm{He}^{1}$, Jimin Zhao $\mathbb{D}^{1,3,4}$ and Kangdong Liu (D) ${ }^{1,2,3,4,5}$
}

(c) The Author(s) 2021

BACKGROUND: Due to the high recurrence and low 5-year survival rates of esophageal squamous cell carcinoma (ESCC) after treatment, the discovery of novel drugs for recurrence chemoprevention is of particular importance.

METHODS: We screened the FDA-approved drug library and found that Nuplazid, an atypical antipsychotic that acts as an effective 5-HT 2 A receptor inverse agonist, could potentially exert anticancer effects in vitro and in vivo on ESCC.

RESULTS: Pull-down results indicated that Nuplazid binds with p21-activated kinase 4 (PAK4), and a kinase assay showed that Nuplazid strongly suppressed PAK4 kinase activity. Moreover, Nuplazid exhibited inhibitory effects on ESCC in vivo.

CONCLUSIONS: Our findings indicate that Nuplazid can suppress ESCC progression through targeting PAK4.

British Journal of Cancer (2022) 126:1037-1046; https://doi.org/10.1038/s41416-021-01651-z

\section{BACKGROUND}

Esophageal cancer is the seventh most commonly diagnosed cancer and the sixth most common cause of cancer-related mortality worldwide [1]. Esophageal squamous cell carcinoma (ESCC) accounts for $\sim 90 \%$ of esophageal cancers [2], and is typically treated with surgery, chemotherapy, radiotherapy and combination therapy $[3,4]$. However, even with treatment, the 5-year overall survival rate has been reported to be $\sim 47 \%$, with $49 \%$ of patients developing locoregional progression or distant progression $[5,6]$. Therefore, it is important to identify novel drugs with low toxicity and high efficacy to prevent the recurrence of ESCC and increase the survival rate of patients. The repositioning of drugs can overcome the challenges of high wastage, high cost, and time-consuming drug development $[7,8]$. Screening drugs approved by the FDA and repositioning their anti-tumour effects have the potential to overcome several challenges associated with drug development and to guarantee rapid clinical trials.

p21-Activated kinase 4 (PAK4) is involved in numerous signaling pathways and plays a pivotal role in cytoskeleton regulation, cell migration, growth, proliferation and survival [9]. The overexpression of PAK4 is reported to be closely related to the occurrence and development of various cancers, including pancreatic [10], breast [11, 12], ovarian [13], and gastric cancers [14]. Currently, several compounds have been identified as PAK4 inhibitors, which typically target the ATP-binding pocket of PAK4 kinase domain [15]. However, the transition from compound inhibitors to clinical medications needs to overcome time-consuming and exorbitant cost factors.
Nuplazid, an atypical antipsychotic that functions as an effective 5-HT $2 \mathrm{~A}$ receptor inverse agonist, is mainly used to treat Parkinson's disease psychosis [16]. In this study, we screened drugs approved by the FDA and found Nuplazid could inhibit the growth of ESCC in vitro. Then our study found that Nuplazid treatment inhibits the growth of ESCC by binding to PAK4 and regulating its downstream signaling pathway interaction. The anticancer effects of Nuplazid on ESCC in vitro and in vivo suggested Nuplazid might be a candidate for ESCC chemoprevention.

\section{METHODS}

\section{Cell culture}

The Shantou human embryonic esophageal (SHEE) cell line was obtained from Dr. Enmin Li (Medical College of Shantou University) [17]. Human esophageal cancer cell lines KYSE150, KYSE410 and KYSE450 cells were purchased from the Type Culture Collection of the Chinese Academy of Science. ESCC cells were cultured in RPMI-1640 medium (Biological Industries, China) supplemented with $10 \%$ inactivated FBS (Biological Industries, China) and 1\% penicillin/streptomycin. The cells were cytogenetically tested by STR- Promega and were authenticated (August, 2014 and July, 2017) $[18,19]$. HEK293T cells (ATCC) were cultured in DMEM medium (Biological Industries, China). All cells were maintained at $37^{\circ} \mathrm{C}$ in a humidified $5 \% \mathrm{CO}_{2}$ incubator.

\section{Reagents and antibodies}

Nuplazid was purchased from J\&K Chemical (Beijing, China). jetPRIME ${ }^{\circledR}$ transfection reagent was purchased from Polyplus Transferion ${ }^{\circledR}$ SA. Protein

\footnotetext{
${ }^{1}$ Pathophysiology Department, School of Basic Medical Sciences, Zhengzhou University, Zhengzhou, Henan, China. ${ }^{2}$ China-US (Henan) Hormel Cancer Institute, Zhengzhou, Henan, China. ${ }^{3}$ Provincial Cooperative Innovation Center for Cancer Chemoprevention, Zhengzhou University, Zhengzhou, Henan, China. ${ }^{4}$ State Key Laboratory of Esophageal Cancer Prevention and Treatment, Zhengzhou, Henan, China. ${ }^{5}$ Cancer Chemoprevention International Collaboration Laboratory, Zhengzhou, Henan, China. ${ }^{6}$ These authors contributed equally: Yaxing Wei, Wenjie Wu, Yanan Jiang. ${ }^{\bowtie}$ email: zhaojimin@zzu.edu.cn; kdliu@zzu.edu.cn
}

Received: 3 April 2021 Revised: 31 October 2021 Accepted: 22 November 2021

Published online: 15 December 2021 
A/G agarose beads was obtained from Santa Cruz. Antibodies to detect PAK4, p-PAK4 (Ser474) and MAPK1 were purchased from CST (Beverly, MA, USA). P-MAPK1 (Thr185/Tyr187) antibody was obtained from Thermo Scientific (Waltham, MA, USA). Antibody to detect Flag was purchased from HuaBio (Hangzhou, China). Ki67 antibody was obtained from Abcam (Cambridge, MA, USA).

\section{Cytotoxicity assay and cell proliferation assay}

Cells (SHEE, KYSE150 and KYSE450; $8 \times 10^{3} /$ well) were seeded in 96-well plates with $0.1 \mathrm{ml}$ of medium containing $10 \%$ FBS. After incubation for $16 \mathrm{~h}, 0.1 \mathrm{ml}$, a medium with different concentrations of Nuplazid was added. After incubation for another $24 \mathrm{~h}$ and $48 \mathrm{~h}$ for cytotoxicity assay and $24,48,72$ and $96 \mathrm{~h}$ for cell proliferation assay, the plates were removed from the incubator. Hundred microlitres of $1 \mu \mathrm{g} / \mathrm{ml}$ DAPI was added to each well after fixing the cells with $4 \%$ paraformaldehyde for $30 \mathrm{~min}$. After incubation at $37^{\circ} \mathrm{C}$ for $20 \mathrm{~min}$, the cells were counted by a high content imaging system (In Cell Analyzer 6000, GE Healthcare).

\section{Anchorage-independent cell growth}

The soft-agar colony formation assay was used to determine the anchorage-independent cell growth. Three millilitres Eagle Basal Medium with $10 \% \mathrm{FBS}$ and $0.6 \%$ agar was added to each well of a six-well plate and solidified at room temperature for $2 \mathrm{~h}$. ESCC cells $\left(8 \times 10^{3} /\right.$ well) were suspended in $1 \mathrm{ml}$ Eagle's Basal Medium (BME) with 10\% FBS and $0.3 \%$ agar and subsequently plated over the solidified bottom layer. After incubation at $37^{\circ} \mathrm{C}$ in $5 \% \mathrm{CO}_{2}$ for 7 days, the colonies were photographed and counted using a high content imaging system (In Cell Analyzer 6000, GE Healthcare).

\section{Plate clone formation assay}

Cells (200/well) were seeded in six-well plates with $2 \mathrm{ml}$ of medium containing $10 \%$ FBS. After $16 \mathrm{~h}$ incubation, $2 \mathrm{ml}$ of medium with different concentrations of Nuplazid was added to each well. After incubation for 7 days, the plates were removed from the incubator and the clones were stained with $0.5 \%$ crystal violet for $15 \mathrm{~min}$ after fixation with $4 \%$ paraformaldehyde for $30 \mathrm{~min}$. Then the clones were photographed and counted.

\section{Cell sample preparation and Phosphoproteome analysis}

KYSE150 $\left(4.5 \times 10^{6}\right.$ cells $)$ were seeded into a $15 \mathrm{~cm}$ dish and treated with $5 \mu \mathrm{M}$ Nuplazid or DMSO for $24 \mathrm{~h}$ as control. For trypsin digestion, protein was extracted from cells using buffer with $8 \mathrm{M}$ urea with $1 \%$ protease inhibitor cocktail. After reduction with $5 \mathrm{mM}$ dithiothreitol at $56{ }^{\circ} \mathrm{C}$ for $30 \mathrm{~min}$, the protein sample was alkylated with $11 \mathrm{mM}$ iodoacetamide for $15 \mathrm{~min}$ RT in darkness. Then $100 \mathrm{mM}$ TEAB was added to dilute samples to a urea concentration less than $2 \mathrm{M}$. Trypsin was added to the sample (according to mass ratio 1:50 trypsin-toprotein) for the first digestion overnight and 1:100 trypsin-to-protein mass ratio for a second $4 \mathrm{~h}$ digestion. After digestion with trypsin, peptide was desalted by Strata X C18 SPE column (Phenomenex) and vacuum-dried according to the manufacturer's protocol for TMT kit/ iTRAQ kit. After reconstitution in $0.5 \mathrm{M}$ TEAB and processing by TMT kit/ ITRAQ kit (Thermo, 90064), peptides were fractionated by high $\mathrm{pH}$ reverse-phase HPLC using Agilent 300Extend C18 column $(5 \mu \mathrm{m}$ particles, $4.6 \mathrm{~mm} \mathrm{ID,} 250 \mathrm{~mm}$ length). The peptides were subjected to NSI source followed by tandem mass spectrometry (MS/MS) in $Q$ ExactiveTM Plus (Thermo) coupled online to the UPLC.

\section{Data analysis}

The resulting MS/MS data were processed using Maxquant search engine (v.1.5.2.8). The results were exported into Excel to facilitate database research. KEGG pathway research was conducted to analyse quantitative protein and phosphorylation sites. $P<0.05$ was evaluated for statistical significance. FDR was set to $<1 \%$.

\section{Knockdown of PAK4 by shRNA}

The shRNA against human PAK4 was inserted into the pLKO.1 vector. Human shPAK4 full hairpin sequence is \#2 CGAGAATGTGGTG GAGATGTA, \#5 CGACCAGCACGAGCAGAAGTT. HEK293T cells were transiently transfected with pLKO.1 or shPAK4 plus PMD2.G and psPAX2. The cells were placed in fresh medium after $4 \mathrm{~h}$. Then the lentivirus enriched culture medium was collected at 24 and $48 \mathrm{~h}$ post-transfection and stored at $-80^{\circ} \mathrm{C}$ until required for use. The KYSE150 and KYSE450 cells were seeded and infected with lentivirus medium supplemented with polybrene $(8 \mu \mathrm{g} / \mathrm{mL}$; YESEN). After $48 \mathrm{~h}$, the infected cells were selected in complete growth medium supplemented with $2 \mu \mathrm{g} / \mathrm{mL}$ of puromycin (Solarbio) for $24-48 \mathrm{~h}$.

\section{Overexpressing of PAK4}

KYSE410 was chosen to construct PAK4 overexpression cell line by screening the expression level of PAK4 in ESCC cell lines. KYSE410 cell $\left(2 \times 10^{6}\right.$ cells) was infected using pLVX-IRES-puro-PAK4 full length plasmid and pLVX-IRES-puro vector as control, the plasmids were transfected into KYSE410 cells using jetPRIME ${ }^{\circledR}$ transfection reagent. After $48 \mathrm{~h}$, KYSE410 cells were harvested to perform western blot, cell proliferation $\left(1.5 \times 10^{3}\right.$ per well), plate clone formation $\left(2 \times 10^{2}\right.$ per well) and soft-agar assay $\left(8 \times 10^{3}\right.$ per well).

\section{Immunoprecipitation}

KYSE150 and KYSE450 $\left(2 \times 10^{6}\right.$ cells) were seeded into a $10 \mathrm{~cm}$ dish and treated with $5 \mu \mathrm{M}$ nuplazid or DMSO for $24 \mathrm{~h}$ as control. Cell pellets were incubated with lysis buffer $(50 \mathrm{mM}$ Tris $-\mathrm{HCl}$ pH 8.0, 0.5\% NP40, $150 \mathrm{mM}$ $\mathrm{NaCl}$ ) for $30 \mathrm{~min}$ at $4{ }^{\circ} \mathrm{C}$. After quantification, appropriate cell lysates were incubated with $40 \mu \mathrm{L}$ of protein A/G agarose beads and rotated for $2 \mathrm{~h}$ at $4{ }^{\circ} \mathrm{C}$. Then collect cell lysate and add PAK 4 antibody, $40 \mu \mathrm{L}$ of protein $\mathrm{A} / \mathrm{G}$ agarose beads was then added to each sample and rotated overnight at $4{ }^{\circ} \mathrm{C}$. The beads were washed four times with lysis buffer, and the immune complexes were eluted at $95^{\circ} \mathrm{C}$ for 5 min with 6 xloading buffer. The immunoprecipitated complexes were then separated by SDS/PAGE and subjected to western blot analysis.

\section{Pull-down assay}

Nuplazid-conjugated Sepharose 4 B beads or Sepharose 4 B beads were incubated with PAK4 protein or cell lysates $(500 \mu \mathrm{g})$ in reaction buffer ( $2 \mathrm{mg} / \mathrm{mL}$ BSA, $50 \mathrm{mM}$ Tris- $\mathrm{HCl} \mathrm{pH} 7.4,200 \mathrm{mM} \mathrm{NaCl}, 5 \mathrm{mM}$ EDTA, $1 \mathrm{mM}$ dithiothreitol, and $0.01 \% \mathrm{NP} 40$ ) at $4{ }^{\circ} \mathrm{C}$ overnight. After the beads were washed three times by wash buffer $(200 \mathrm{mM} \mathrm{NaCl}, 50 \mathrm{mM}$ Tris $\mathrm{pH} 7.4$, $5 \mathrm{mM}$ EDTA, $0.01 \% \mathrm{NP} 40$, and $1 \mathrm{mM}$ dithiothreitol), the proteins were eluted from the beads through boiling in loading buffer at $95^{\circ} \mathrm{C}$ for $5 \mathrm{~min}$. Protein binding was then assessed using Western blotting.

\section{Western blot analysis}

Cells were seeded into a $15 \mathrm{~cm}$ dish at $4.5 \times 10^{6}$ cells/well and treated with Nuplazid for $24 \mathrm{~h}$. Total protein was extracted from cells using RIPA lysate buffer. Protein samples ( $30 \mu \mathrm{g}$, quantified by the BCA Protein Assay Kit) were boiled with loading buffer at $98^{\circ} \mathrm{C}$ for $8 \mathrm{~min}$ and then were subjected to SDS-PAGE and transferred to a PVDF membrane (Immobilon ${ }^{\circledR}-\mathrm{P}$ Membrane). After blocking with $5 \%$ non-fat milk for $1 \mathrm{~h}$ at room temperature, the membrane was incubated with primary antibody at $4{ }^{\circ} \mathrm{C}$ overnight. The next day, the membrane was incubated with the corresponding secondary antibody at room temperature for $2 \mathrm{~h}$ after being washed three times with TBST. Protein bands were visualised using the enhanced chemiluminescence $\left(\mathrm{ECL}\right.$, Meilunbio $\left.^{\circledR}\right)$.

\section{In vitro kinase assay}

The activity of PAK4 was determined in a kinase reaction buffer with $200 \mu \mathrm{M}$ ATP, in the presence of the kinase (100 ng of His-PAK4) and $200 \mathrm{ng}$ of the substrate (His-MAPK1) at $30^{\circ} \mathrm{C}$ for $30 \mathrm{~min}$. The reaction was stopped by adding sample loading buffer and heating at $100^{\circ} \mathrm{C}$ for $5 \mathrm{~min}$. The kinase activity was visualised by detecting the indicated antibodies with -western blotting.

\section{Computational modeling of PAK4 with Nuplazid}

For in silico docking of Nuplazid and PAK4, we used the Maestro 11.5 software program. To model the binding of Nuplazid with PAK4, the crystal structure of PAK4 (PDB number $2 \mathrm{cdz}$ ) was downloaded from the PDB database (www. $\mathrm{rcsb} .0 \mathrm{rg} / \mathrm{pdb}[\mathrm{PDB}])$. And water molecules in the structure were removed and hydrogen atoms were added to the protein prior to docking. The structure of Nuplazid was downloaded from PubChem database (https://pubchem.ncbi. nlm.nih.gov/) for the docking study. The PyMOL program was used to prepare the Nuplazid for the docking study.

\section{PDX mouse model}

This study was approved under guidelines established by the Bioethics Committee of Zhengzhou University and followed guidelines set by the 
a

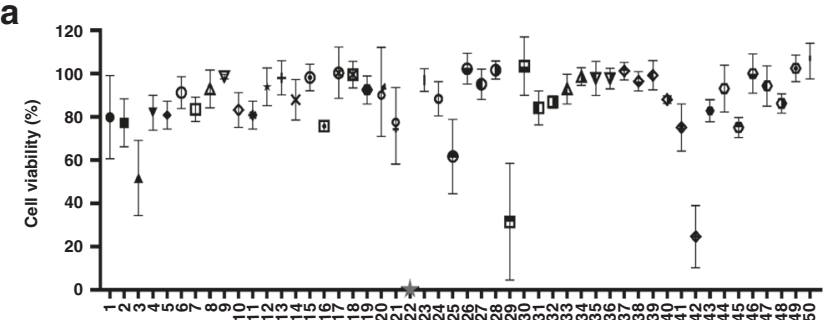

b
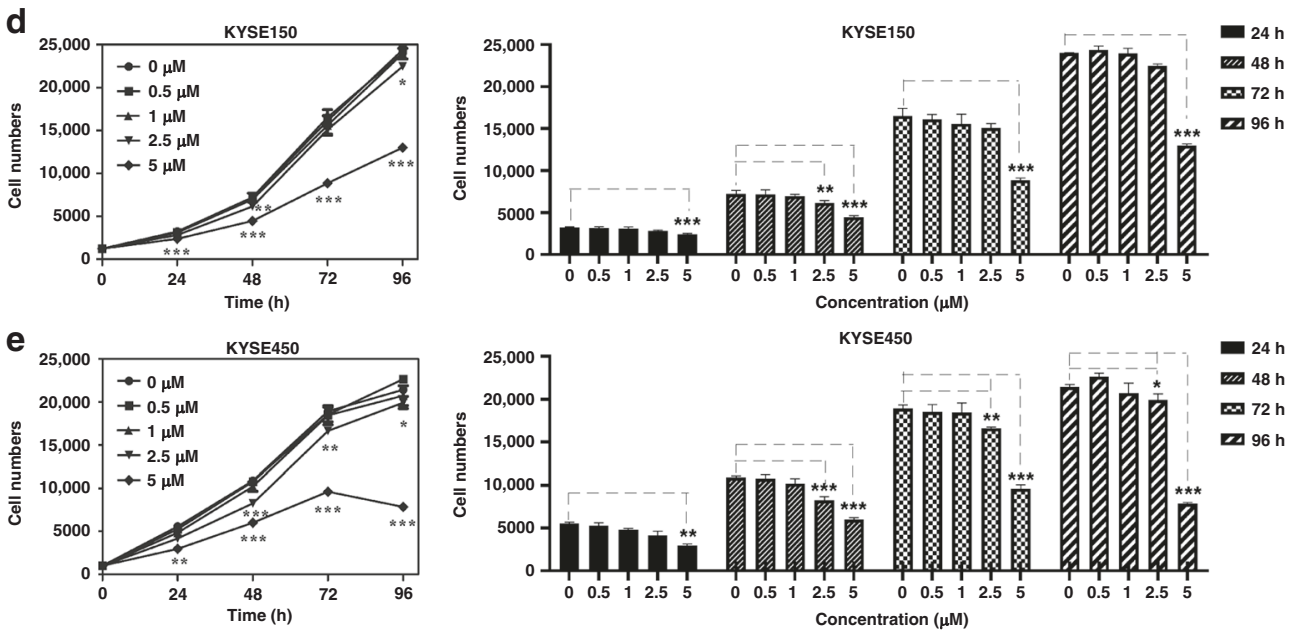

$\mathbf{f}$
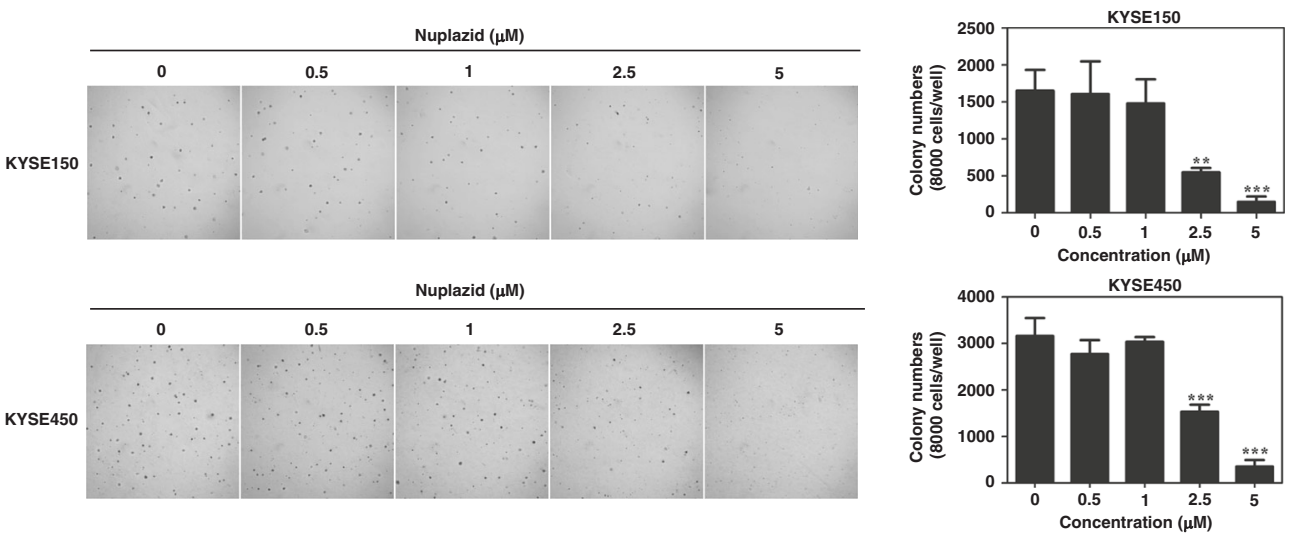

$\mathbf{g}$
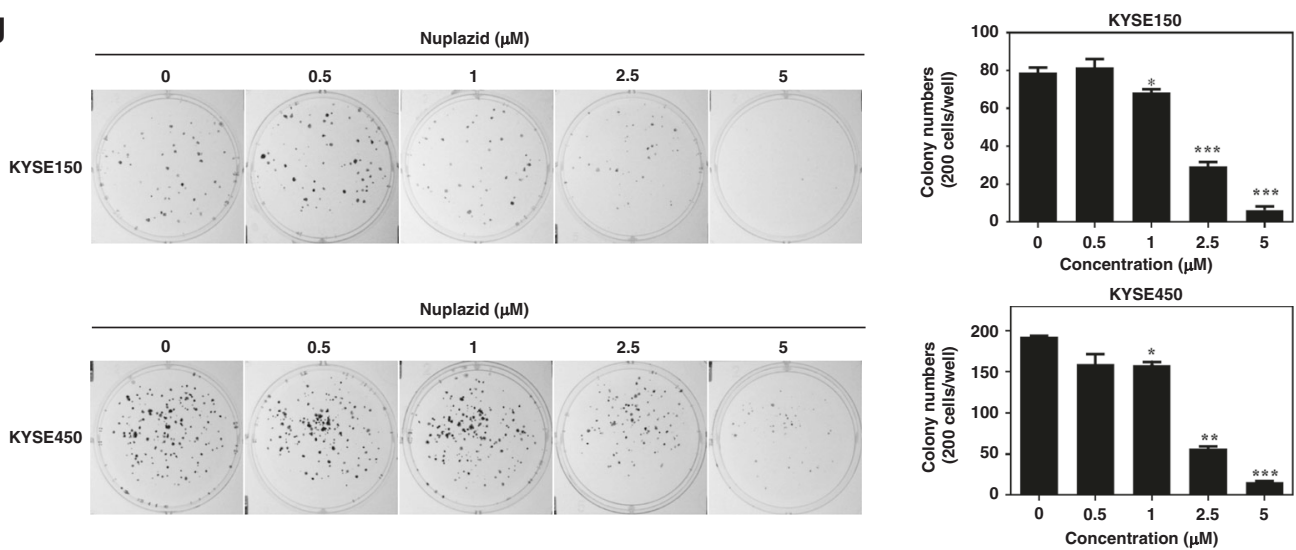

Fig. 1 Nuplaid inhibits the proliferation of ESCC cells. a Nuplazid was screened from the drug library by cell cytotoxicity. b Chemical structure of Nuplazid. c IC50s of Nuplazid in KYSE150 cells, KYSE450 cells and SHEE cells. IC50s were calculated based on day 5 data of various doses of drug treatment. The KYSE150 cells (d) and KYSE450 cells (e) were treated with different doses of Nuplazid (0, $0.5,1,2.5$ and $5 \mu M)$ and cell numbers were calculated at $0,24,48,72$ and $96 \mathrm{~h}$ by analysis at IN Cell Analyzer 6000 . f KYSE150 cells and KYSE450 cells ( $8 \times 10^{3} /$ well) were exposed to different concentrations of Nuplazid $(0,0.5,1,2.5$ and $5 \mu \mathrm{M})$ for 8 days. Colonies were counted for analysis by IN Cell Analyzer 6000 soft-agar program. g KYSE150 and KYSE450 cells (200/well) were treated with different concentrations of Nuplazid (0, $0.5,1,2.5$ and $5 \mu$ M) and incubated for 8 days. Colonies were detected using the crystal violet stain assay. All data are shown as means \pm S.D. The asterisks (*, $\left.{ }^{* *},{ }^{* * *}\right)$ indicate a significant decrease $(p<0.05, p<0.01, p<0.001$, respectively). 
Table 1. The table showed the survival rate of KYSE450 cells which were treated with $50 \mu \mathrm{M}$ different compounds for $48 \mathrm{~h}(n=3)$.

\begin{tabular}{|c|c|c|c|}
\hline & Compound & Cell viability & Error amount \\
\hline 1 & Oxytetracycline & 79.88741 & 19.22323 \\
\hline 2 & Furaltadone hydrochloride & 77.24526 & 11.11366 \\
\hline 3 & Nitrofurazone & 51.82093 & 17.36424 \\
\hline 4 & Chloroxylenol & 82.00295 & 8.014399 \\
\hline 5 & Benzocaine & 80.89498 & 6.461878 \\
\hline 6 & Chlorobutanol & 91.27302 & 7.388945 \\
\hline 7 & Ofloxacin & 83.53816 & 5.590931 \\
\hline 8 & Topiramate & 92.96267 & 8.695055 \\
\hline 9 & Betahistine mesylate & 98.62139 & 1.031306 \\
\hline 10 & Adrenosterone & 83.23309 & 8.027643 \\
\hline 11 & $\begin{array}{l}\text { Spectinomycin } \\
\text { dihydrochloride }\end{array}$ & 73.83655 & 9.928254 \\
\hline 12 & $\begin{array}{l}\text { Dihydrostreptomycin } \\
\text { sulfate }\end{array}$ & 93.95017 & 8.7414 \\
\hline 13 & Guaifenesin & 98.01176 & 7.893334 \\
\hline 14 & $\begin{array}{l}\text { Adenosine } 5^{\prime}- \\
\text { monophosphate }\end{array}$ & 87.95408 & 9.379032 \\
\hline 15 & Geniposide & 98.22132 & 6.085869 \\
\hline 16 & Flumethasone & 75.76876 & 2.51898 \\
\hline 17 & $\begin{array}{l}\text { Sparteine sulfate } \\
\text { pentahydrate }\end{array}$ & 100.395 & 11.87379 \\
\hline 18 & Kanamycin sulfate & 99.56081 & 6.104918 \\
\hline 19 & Alodan & 92.51785 & 6.457572 \\
\hline 20 & Terconazole & 91.62695 & 20.55539 \\
\hline 21 & Phenacetin & 75.90553 & 17.62029 \\
\hline Number & Compound & Cell viability & Error amount \\
\hline 22 & Pimavanserin Tartrate & 0.477261 & 0.66110811 \\
\hline 23 & Pyridoxine hydrochloride & 97.07729 & 5.264602 \\
\hline 24 & Salicylic acid & 88.3694 & 7.935546 \\
\hline 25 & Magnolol & 61.72762 & 17.17745 \\
\hline 26 & Gastrodin & 102.2996 & 7.196228 \\
\hline 27 & Piperine & 95.13027 & 7.026235 \\
\hline 28 & Chrysophanic Acid & 101.6242 & 4.183081 \\
\hline 29 & Terandrine & 31.56692 & 26.94679 \\
\hline 30 & Ligustrazine hydrochloride & 103.4953 & 13.47551 \\
\hline 31 & Proanthocyanidins & 84.17642 & 7.867275 \\
\hline 32 & $\begin{array}{l}\text { Glycyrrhetinic acid } \\
\text { (Enoxolone) }\end{array}$ & 86.90683 & 2.867116 \\
\hline 33 & Chondroitine sulfate & 92.9459 & 6.847844 \\
\hline 34 & Scoparone & 98.63513 & 4.068273 \\
\hline 35 & Mepenzolate bromide & 97.80974 & 7.847292 \\
\hline 36 & Benzthiazide & 97.71037 & 4.752846 \\
\hline 37 & Limonin & 101.2372 & 4.037471 \\
\hline 38 & Imperatorin & 96.49294 & 4.462271 \\
\hline 39 & Puerarin(Kakonein) & 99.2533 & 6.754354 \\
\hline 40 & Baicalein & 88.01013 & 1.756159 \\
\hline 41 & Sulfasalazine & 75.18233 & 10.88988 \\
\hline 42 & Chlorquinaldol & 24.70887 & 14.34594 \\
\hline Number & Compound & Cell viability & Error amount \\
\hline 43 & Nalidixic acid & 82.85737 & 5.105331 \\
\hline 44 & Cefotaxime sodium salt & 93.12401 & 10.8226 \\
\hline & & & \\
\hline
\end{tabular}

Table 1. continued

\begin{tabular}{|llcc|} 
Number & Compound & Cell viability & Error amount \\
\hline 46 & Sulfamerazine & 100.0874 & 9.097454 \\
\hline 47 & Sulfaquinoxaline sodium & 94.32887 & 9.286951 \\
\hline 48 & Trimebutine & 86.24522 & 4.442833 \\
\hline 49 & Ambroxol & 102.4955 & 6.136034 \\
\hline 50 & Sulfabenzamide & 105.8144 & 8.254695 \\
\hline
\end{tabular}

Institutional Animal Care and Use Committee (CUHCI2019002, CUHCI2021001, and $\mathrm{CUHCI} 2021005)$. SCID-CB17 mice were purchased from Charles River and kept under specific pathogen-free conditions. ESCC tissues were obtained from the First Affiliated Hospital of Zhengzhou University, and written informed consent for the use of the tissue samples was provided by all patients. ESCC fragments of $\sim 1-2 \mathrm{~mm}^{3}$ were seeded under the skin of the mice. Mice were randomly divided into three groups of eight animals each as follows: (1) untreated vehicle group; (2) $11 \mathrm{mg}$ Nuplazid/kg of body weight and (3) $44 \mathrm{mg}$ Nuplazid/kg body weight. Mice were given Nuplazid or vehicle (10\% DMSO in $0.9 \%$ saline) by gavage every day. Tumour volume was calculated by the following formula: tumour volume $\left(\mathrm{mm}^{3}\right)=\left(\right.$ length $\times$ width $\left.{ }^{2}\right) / 2$. When the tumour volume reached $\sim 1000 \mathrm{~mm}^{3}$, the mice were anesthetised, and the tumour weight was measured.

\section{Immunohistochemistry analysis}

After fixation with $4 \%$ formaldehyde for at least $48 \mathrm{~h}$, tumour tissues were embedded in paraffin blocks and subjected to immunohistochemistry (IHC). Serial $4 \mu \mathrm{m}$ paraffin tissue sections were rehydrated using alcohol and TBST after being deparaffinised at $60^{\circ} \mathrm{C}$ for $2 \mathrm{~h}$. Next, the slides were boiled in sodium citrate buffer solution for $15 \mathrm{~min}$. Afterwards, the tissue sections were treated with $3 \% \mathrm{H}_{2} \mathrm{O}_{2}$ for $8 \mathrm{~min}$. For $\mathrm{IHC}$, tissues were hybridised with the Ki67 and p-MAPK $1^{\text {T185/Y187 }}$ primary antibody (1:50) at $4{ }^{\circ} \mathrm{C}$ overnight. Then the slides were incubated with HRP-IgG secondary antibody after being washed with TBST. Finally, the slides were stained with diaminobenzidine (DAB) for $2 \mathrm{~min}$ and then counterstained with hematoxylin. All sections were scanned using Tissue Faxes (TissueGnostics, version 4.2) and the Image Pro Plus software program (Media Cybernetics, Rockville, MD) was used to calculate positive cells.

\section{Statistical analysis}

All quantitative results are expressed as mean values \pm SD from three times replicates. SPSS 21.0 was applied to evaluate significant difference. Oneway ANOVA or a non-parametric test was used for statistical analysis; $p<$ 0.05 was considered statistically significant.

\section{RESULTS}

\section{Nuplazid inhibited the proliferation of ESCC cells}

To select a drug that can effectively suppress ESCC proliferation, we screened an FDA-approved drug library with a toxicity assay. We found Nuplazid (compound number 22) exhibited toxic effects on KYSE450 cells (Fig. 1a). The specific information of the compound is in Table 1 of the Supplementary data. Nuplazid is a 5-HT 2 A receptor inverse agonist (Fig. $1 \mathrm{~b}$ ) that is mainly used to treat Parkinson's disease. The IC50 of Nuplazid on ESCC cells and immortalised epithelial cells was evaluated by a cell cytotoxicity assay. The results indicated that Nuplazid exhibited more toxic effects on KYSE150 and KYSE450 cells compared to SHEE cells (Fig. 1C and Fig. S1). To determine the inhibitory effect of Nuplazid on ESCC, KYSE150 and KYSE450 cells were treated with Nuplazid $(0,0.5,1,2.5$ and $5 \mu \mathrm{M})$. The results indicated that Nuplazid effectively suppressed the growth of ESCC cells in a dose-dependent manner (Fig. 1d, e). We next investigated whether Nuplazid could inhibit anchorage-independent growth of ESCC cells. The soft-agar assay showed that Nuplazid could significantly block the anchorage-independent growth of KYSE150 and KYSE450 cells in a dose-dependent manner (Fig. 1f). In addition, the growth inhibitory effect of Nuplazid on ESCC was 
a
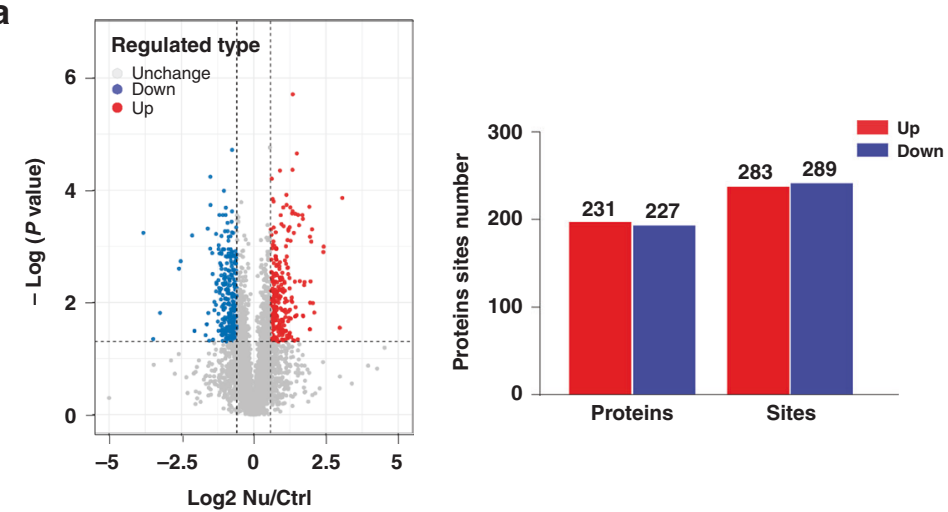

C

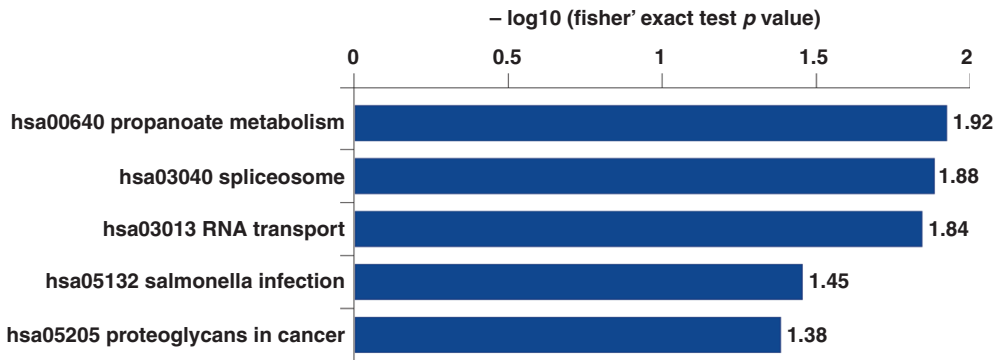

b

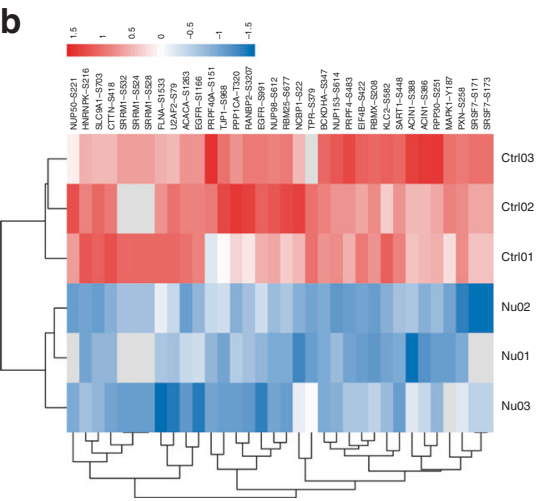

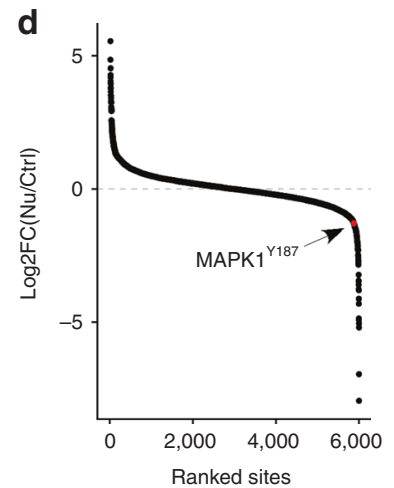

e

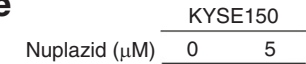
GAPDH

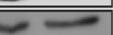
\begin{tabular}{rlr} 
& \multicolumn{2}{l}{ KYSE450 } \\
Nuplazid $(\mu \mathrm{M})$ & $0 \quad 5$ \\
p-MAPK1 $1185 /$ Y 187 & $=$ \\
GAPDH &
\end{tabular}

Ranked sites

Fig. 2 PAK4 kinase activity changes of KYSE150 cells after Nuplazid treatment. a Volcano plot shows that 572 unique phosphosites changed significantly ( $t$-test $P$-value $<0.05$, FDR $<0.01$ upon $24 \mathrm{~h}$ treatment with $5 \mu \mathrm{M}$ Nuplazid). Blue dots represent downregulated proteins, and red dots represent upregulated proteins, with 283 sites up and 289 sites down. $\mathbf{b}$ These phosphoproteins which were downregulated are mapped to Heat map upon Nuplazid treatment. c KEGG pathways that are significantly downregulated in phosphorylation are shown according to $P$-value. d Averaged quantitative phosphosites from the phosphoproteomic, the locations of MAPK $1{ }^{Y 187}$ were ranked according to their Log2 FC between the DMSO and Nuplazid-treated cells. e Effect of Nuplazid treatment for $24 \mathrm{~h}$ on $\mathrm{p}-\mathrm{MAPK} 1^{\mathrm{T} 185 / \mathrm{Y} 187}$ in KYSE150 and KYSE450 cells.

evaluated. The results of the plate clone formation assay also indicated that clone formation in KYSE150 and KYSE450 cells was inhibited after Nuplazid treatment (Fig. 1g). Together, these results indicate that Nuplazid inhibits ESCC cell growth in vitro.

\section{Nuplazid affects PAK4/MAPK1 signaling}

To investigate the anticancer mechanism of Nuplazid in ESCC cells, KYSE150 cells were treated with $5 \mu \mathrm{M}$ Nuplazid or DMSO for $24 \mathrm{~h}$ as a control. Subsequently, we analysed proteomic and phosphorylation changes after Nuplazid treatment by performing mass spectrometry. The quality control report indicated that this test was in line with the standards (Fig. S2A and B). According to proteomic and phosphoproteomic analysis, 5165 proteins were quantified from 6449 proteins, and 5988 phosphorylation sites were quantified from 8852 sites. To evaluate statistical significance, strict criteria ( $t$-test $P$-value $<0.05$, FDR $<0.01$ ) were applied to three biological replicates. Among all the quantified phosphosites, we discovered that 572 phosphosites were changed by 283 sites up and 289 sites down according to $P$-value $<0.05$ (fold change $>1.5$ or fold change $<0.67$ ) (Fig. 2a). A series of phosphosites were differentially expressed in KYSE150 cells after Nuplazid treatment (Fig. 2b). The quantified phosphorylation sites were mapped to the KEGG signaling pathway, and the top five signaling pathways are shown in a KEGG pathway enrichment map (Fig. 2c). Based on the dataset, all changed phosphorylation sites are determined and the phosphorylation site of MAPK1 at 187 was a visible downregulated site (Figs. $2 \mathrm{~d}$ and S2C). Western blot analysis revealed that the level of $\mathrm{p}-\mathrm{MAPK}^{\mathrm{Y} 187}$ was decreased in KYSE150 and KYSE450 cells treated with Nuplazid for $24 \mathrm{~h}$ (Fig. 2e). To identify the upstream kinases that regulate these proteins, the upstream kinase was predicted based on changes in protein phosphorylation sites, which showed that the kinase activity of PAK4 may be regulated by Nuplazid (Fig. S3). Meanwhile, Swiss Target also predicted PAK4 may be the target protein of Nuplazid (Fig. S3). We found that PAK4 and MAPK1 were positively correlated by TCGA database analysis (Fig. S3). Therefore, we hypothesised that Nuplazid may target PAK4 and regulate its downstream signaling pathway.

\section{Nuplazid could bind to PAK4}

To better understand how Nuplazid binds with PAK4, we created a computational docking model through Maestro 11.5. The docking result indicated that Nuplazid formed hydrogen bonds with PAK4 (Fig. 3a). Then in vitro pull-down assay was performed to confirm the computational docking results of Nuplazid with PAK4, we used Nuplazid-conjugated Sepharose 4 B beads (or Sepharose 4 B beads only as a control) and a recombinant PAK4 protein (Fig. 3b), HEK293F cell lysates that overexpressed PAK4 (Fig. 3c), KYSE150 lysate (Fig. 3d), or KYSE450 lysate (Fig. 3e). These results indicated Nuplazid can bind to PAK4 in vitro and ex vivo. The previous docking result indicated that Nuplazid might bind with PAK4 at ATP-binding sites ILE327, ALA402 and ASP444. Therefore, mutant PAK4 (I327A, D444A) was constructed and ectopically expressed in HEK293 F cells. Then pull-down assays using Nuplazid-conjugated Sepharose 4 B beads and HEK293F cell lysates that overexpressed PAK4 wild type protein or PAK4 mutant protein revealed that 

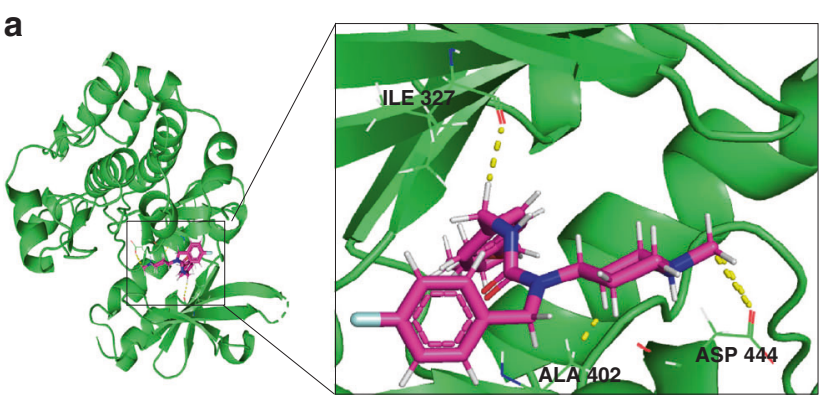

b

c

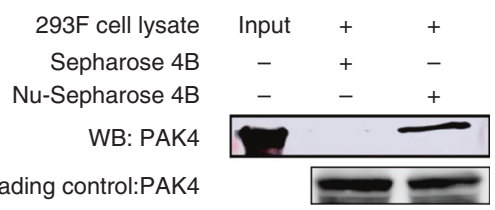

e
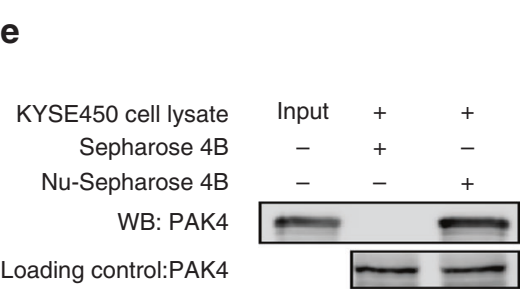

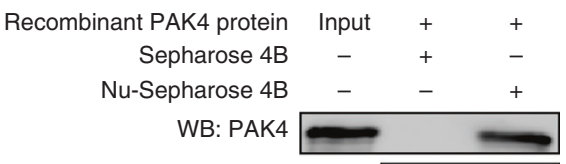

Loading control:PAK4

d

\begin{tabular}{rccc} 
KYSE150 cell lysate & Input & + & + \\
Sepharose 4B & - & + & - \\
Nu-Sepharose 4B & - & - & + \\
WB: PAK4 & & & \\
\cline { 2 - 4 } Loading control:PAK4 & &
\end{tabular}

f

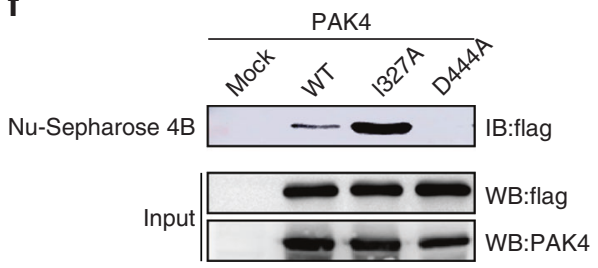

Fig. 3 Nuplazid directly binds to PAK4. a Modeling of Nuplazid binding with PAK4. The recombinant protein or cell lysate was incubated with Nuplazid-conjugated Sepharose 4B beads or with Sepharose 4B beads alone. Nuplazid directly binds to PAK4 in recombinant proteins (b) or $293 \mathrm{~F}$ cell lysates which overexpressed PAK4 (c) or KYSE150 lysate (d) or KYSE450 lysate (e) or cells (f) ectopically expressing PAK4 (WT, mutant I327A, or D444A). Proteins were pulled down and then analysed by western blotting using antibodies to detect PAK4. For b-f, similar results were obtained from independent experiments.
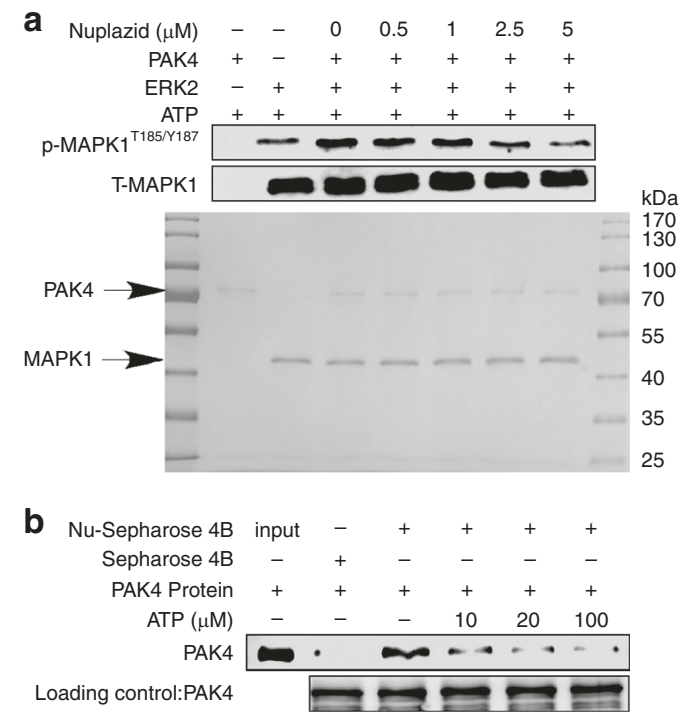

C

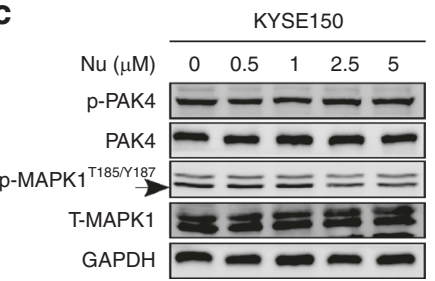

d

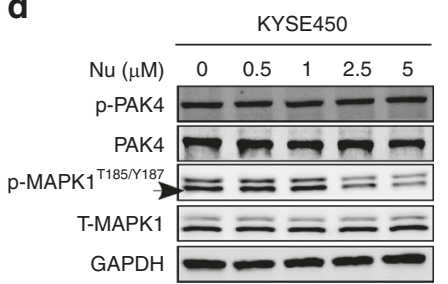

e

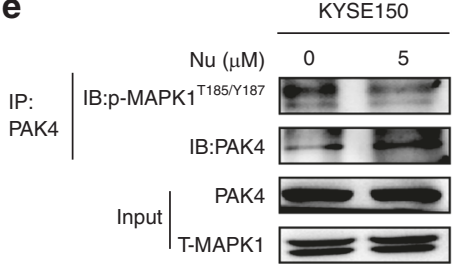

$\mathbf{f}$

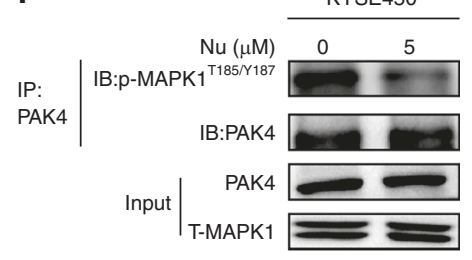

Fig. 4 Nuplazid inhibits the kinase activity of PAK4. a PAK4 kinase activity was assessed by an in vitro kinase assay using active PAK4 and inactive MAPK1 proteins. The effect of Nuplazid was determined by western blot analysis using a p-MAPK $1^{\mathrm{T} 185 / Y 187}$ antibody. b Nuplazid binds with PAK4 in an ATP-competitive manner. Active PAK4 was incubated with ATP at different concentrations $(10,20$ or $100 \mu \mathrm{M})$ and $100 \mu \mathrm{l}$ of Nuplazid-sepharose 4B or sepharose 4B (as a negative control) in reaction buffer. The level of p-PAK4, PAK4, p-MAPK1 and T-MAPK1 in KYSE150 cells (c) and KYSE450 cells (d) with different concentration of Nuplazid (0, 0.5, 1, 2.5 and $5 \mu \mathrm{M})$ treatment for $24 \mathrm{~h}$ was determined by western blotting. The level of p-MAPK $1^{\mathrm{T} 185 / Y 187}$ was affected by PAK4 in KYSE150 cells (e) and KYSE450 cells (f) which treated with Nuplazid. MAPK1 was immunoprecipitated by PAK4 and MAPK1 was detected by P-MAPK1 $1^{\text {T185/Y187. }}$

D444 A of PAK4 had the greatest reduction binding affinity with Nuplazid (Fig. 3f), suggesting that the ASP444 site is important for the binding of Nuplazid with PAK4. Our results indicated that Nuplazid directly binds to PAK4.

\section{Nuplazid inhibited the kinase activity of PAK4}

To identify whether Nuplazid could regulate the kinase activity of PAK4, we used a recombinant active PAK4 protein and inactive MAPK1 protein to perform an in vitro kinase assay. The results 
a
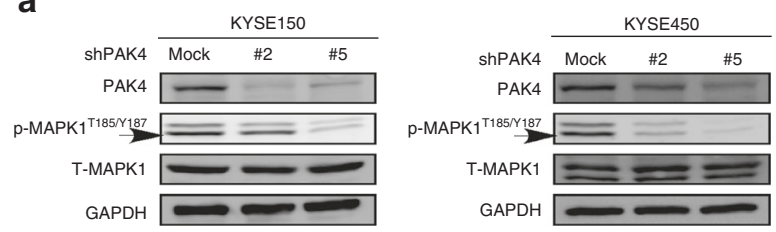

b
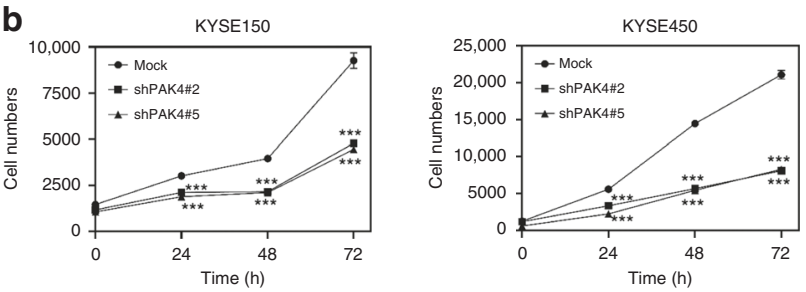

C
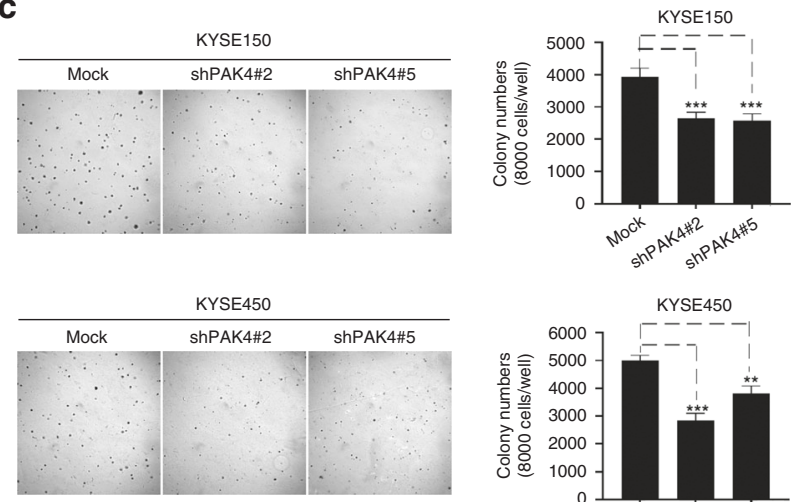

d

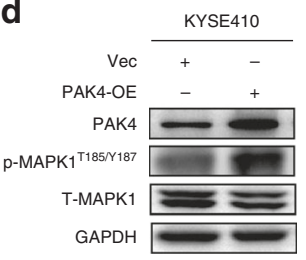

e

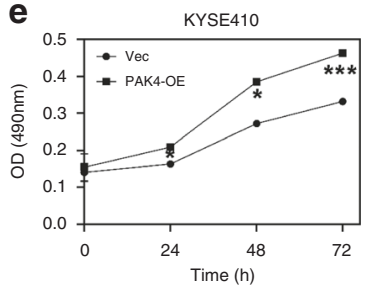

f
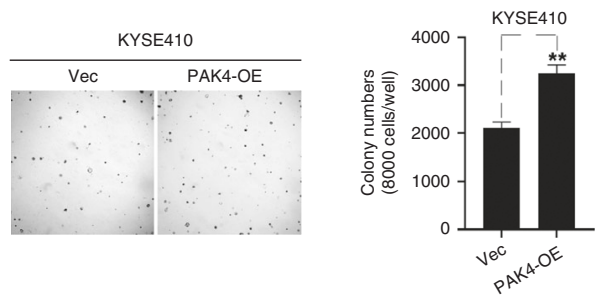

g
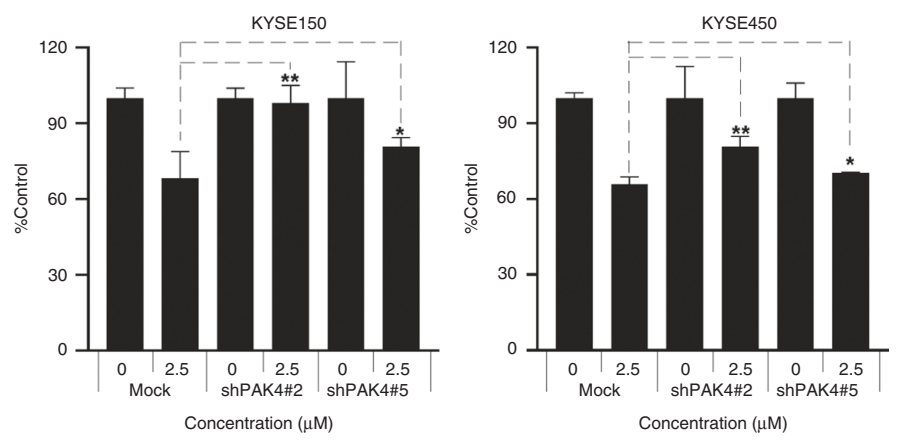

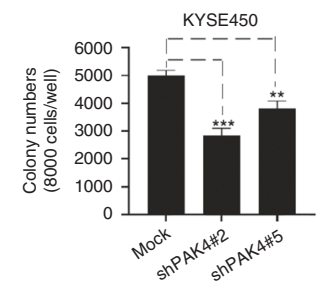

Fig. 5 Nuplazid inhibits ESCC growth through PAK4. a The knockdown efficiency of PAK4 by shRNA (\#2, \#5) in KYSE150 and KYSE450 cells was evaluated by Immunoblotting. And the level of the PAK4 downstream signal MAPK in the shPAK4 cells was detected by WB. b Cell numbers of KYSE150 and KYSE450 cells with transfected shPAK4 at 0, 24, 48 and 72 h. c Colonies were counted for KYSE150 and KYSE450 cells with transfected with shPAK4 after 7 days. $\mathbf{d}$ The overexpression efficiency of PAK4 in KYSE410 cells was evaluated by WB and the level of the PAK4 downstream signal MAPK1 in the KYSE410 cells with transfected PAK4 was detected by WB. e Cell numbers of KYSE410 cells with transfected PAK4 at 0, 24, 48 and $72 \mathrm{~h}$. f Colonies were counted for KYSE410 cells with transfected PAK4 after 7 days. $\mathrm{g}$ The KYSE150 cells and KYSE450 cells were treated with $2.5 \mu \mathrm{M}$ Nuplazid for $96 \mathrm{~h}$, and the inhibition rate was calculated. All data are shown as means \pm S.D. The asterisks $(* * * * * *)$ indicate a significant decrease $(p<0.05, p<0.01, p<0.001$, respectively).

verified that Nuplazid could suppress the phosphorylation of MAPK1 (Fig. 4a). Because Nuplazid inhibited PAK4 kinase activity and could bind with PAK4 at ATP-binding sites ASP444, we performed pull-down assays with ATP to investigate how Nuplazid interacts directly with PAK4 kinase. The binding of Nuplazid to PAK4 decreased in the presence of ATP (Fig. 4b), indicating that Nuplazid suppresses the kinase activity of PAK4 by an ATPcompetitive manner. We next determined whether the PAK4 downstream signaling in ESCC cells could be affected by Nuplazid. After treatment with Nuplazid for $24 \mathrm{~h}$, the proteins in KYSE150 and KYSE450 cells were extracted and PAK4 signaling pathway molecules were detected by Western blotting. Results indicated Nuplazid inhibited MAPK1 phosphorylation in a dose-dependent manner, whereas PAK4 and phosphorylated PAK4 remained unchanged (Fig. 4c, d). To further determine whether Nuplazid could affect PAK4 interact with MAPK1, KYSE150 cells and KYSE450 cells treated with Nuplazid. PAK4 was used to immunoprecipitate MAPK1 and p-MAPK1 $1^{\text {T185/Y187 }}$ was used to detect p-MAPK $1^{\mathrm{T} 185 / \mathrm{Y} 187}$ by Western blot analysis. The results indicated that PAK4 can combine with MAPK1 and Nuplazid could decreased the level of $\mathrm{p}-\mathrm{MAPK} 1^{\mathrm{T} 185 / \mathrm{Y} 187}$ through affected the kinase activity of PAK4 (Fig. 4e, f).

\section{Nuplazid suppressed ESCC growth through PAK4}

To investigate whether PAK4 knockdown might mediate the growth of ESCC, we established multiple PAK4 knockdown cell lines. Western blotting results showed that the expression of PAK4 in cells transfected with two individual PAK4 shRNA was significantly decreased compared with control cells (Fig. 5a). And the level of p-MAPK1 $1^{\text {T185/Y187 }}$ was decreased in PAK4 knockdown cells (Fig. 5a). Then we used cell proliferation and anchorage-independent cell growth assays to assess whether the knockdown of PAK4 inhibits the growth of ESCC. Cells with PAK4 knockdown exhibited slower growth and colony formation compared to control sh-mock cells (Fig. 5b, c). To further provide PAK4 plays an active role in ESCC, we assessed whether overexpression of PAK4 could promote cell proliferation in ESCC cells. First, we detected the expression levels of PAK4 in different ESCC cell lines, and the results showed that PAK4 was lowly expressed in KYSE410 cells (Fig. S4). Then we established PAK4 overexpressing KYSE410 cells. The Western blot result showed that the expression of PAK4 in KYSE410 cells was significantly higher than control cells that expressed the empty PLVX-IRES-puro vector (Fig. 5d) and the level of p-MAPK1 ${ }^{\text {T185/Y187 }}$ was increased in PAK4 overexpressing cells (Fig. 5d). As expected, overexpression of 
a

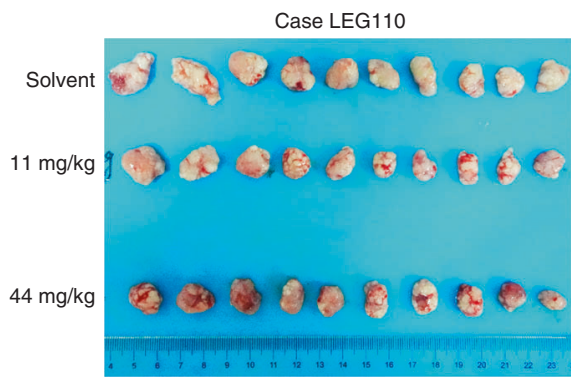

d

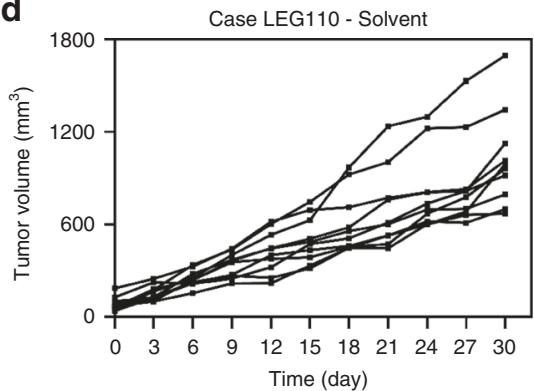

b

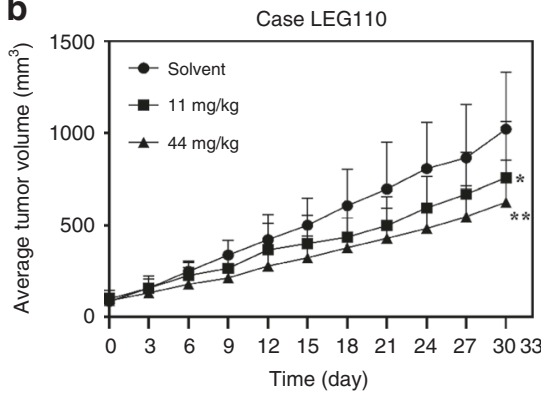

C
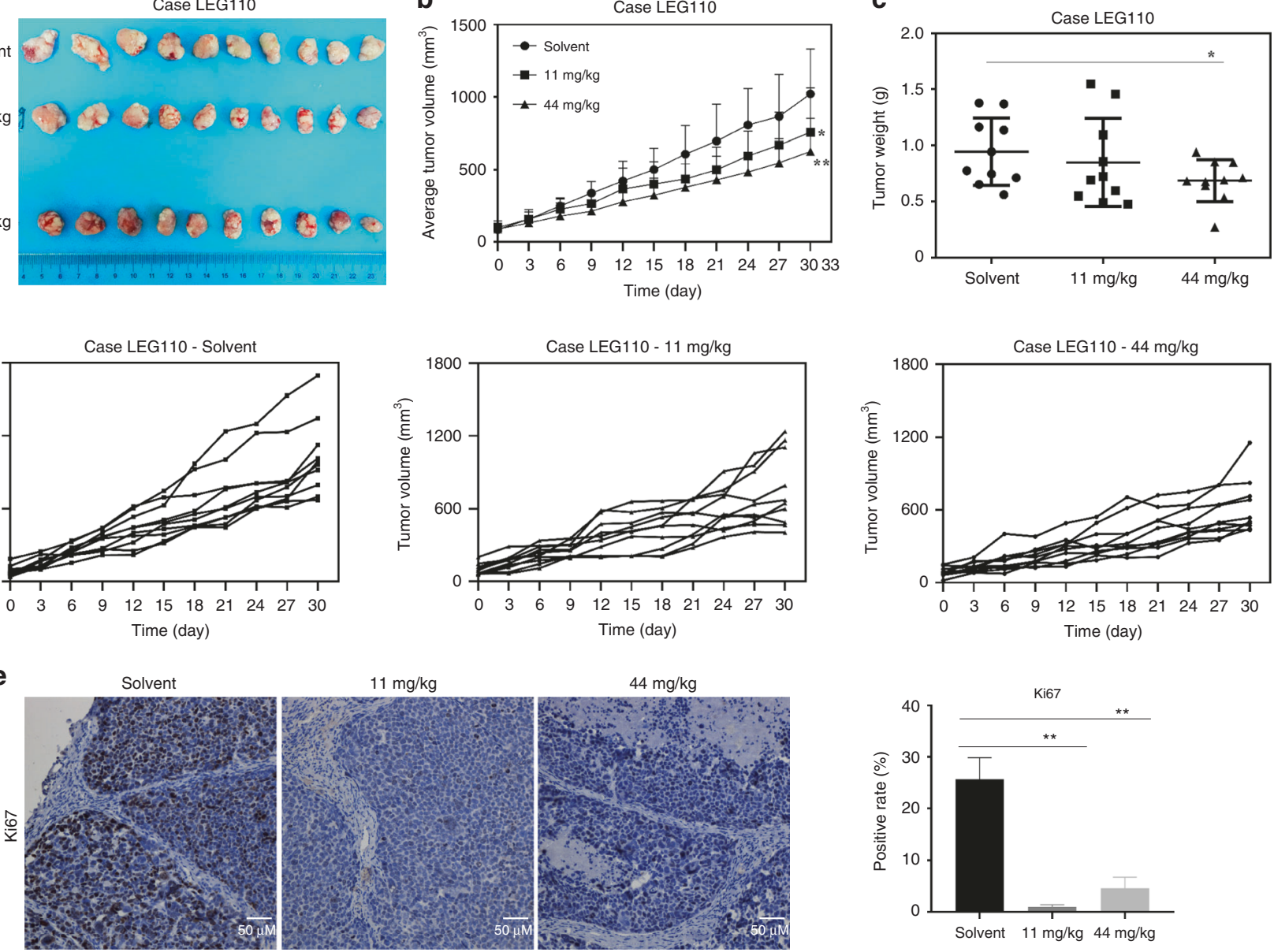

f

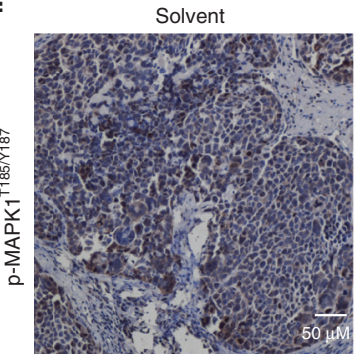

$11 \mathrm{mg} / \mathrm{kg}$
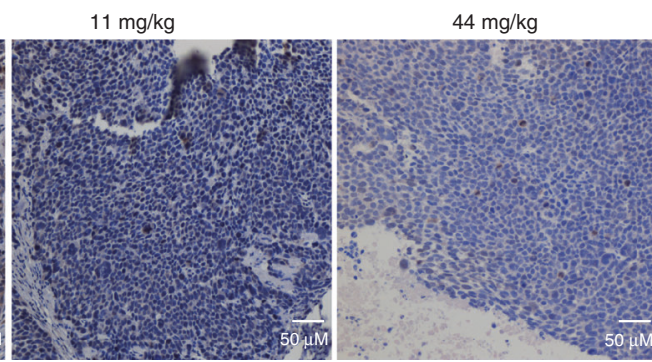
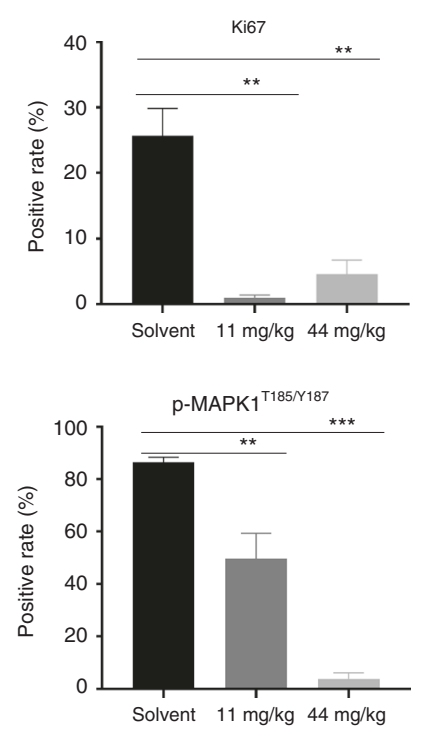

Fig. 6 Nuplazid inhibits the growth of esophageal cancer patient-derived xenograft tumours in vivo. a The photograph showed tumour tissues from PDX mice treated with solvent or Nuplazid $(11 \mathrm{mg} / \mathrm{kg}$ or $44 \mathrm{mg} / \mathrm{kg})$. b Tumour volumes were measured every 3 days. c After sacrificing, isolated tumours were weighted. $\mathbf{d}$ Data recorded tumour size of individual mice. Immunohistochemistry analysed the level of ki67 $(\mathbf{e})$ and p-MAPK $1^{\mathrm{T} 185 / \mathrm{Y} 187}$ (f) in tumour tissues from treated or untreated groups of mice. All data are shown as means \pm S.D. The asterisks $\left(*{ }^{* *}\right.$, ***) indicate a significant decrease $(p<0.05, p<0.01, p<0.001$, respectively).

PAK4 significantly promoted the cell growth (Fig. 5e) and colony formation (Fig. 5f) compared to control cells. Taken together, these data demonstrated that the PAK4 play an important role in ESCC cells.

To verify whether Nuplazid affects the proliferation of esophageal cancer cells through PAK4, shPAK4-KYSE150, shPAK4-KYSE450 cells and their control sh-mock cells were treated with $2.5 \mu \mathrm{M}$ Nuplazid. The results indicated the growth of cells with PAK4 knockdown was less inhibited compared to control sh-mock cells (Fig. 5g). In summary, Nuplazid inhibits ESCC growth through PAK4.

\section{Nuplazid suppressed ESCC PDX tumour growth in vivo}

To examine the anti-tumour activity of Nuplazid against the growth of ESCC tissues in vivo, ESCC PDXs models were established in mice. To determine the dose of Nuplazid for the in vivo experiment, we performed a potential toxicity profile of Nuplazid. Based on the daily oral dose in humans, mice were administered Nuplazid at $11 \mathrm{mg} / \mathrm{kg}$ or $44 \mathrm{mg} / \mathrm{kg}$ every day by gavage for 2 weeks. The results indicated that there was no body weight change in mice between the Nuplazid-treated group (11 mg/kg or $44 \mathrm{mg} / \mathrm{kg}$ ) and the vehicle-treated group (Fig. S5). Therefore, mice were administered Nuplazid at either $11 \mathrm{mg} / \mathrm{kg}$ or $44 \mathrm{mg} / \mathrm{kg}$ daily by gavage over a period of 30 days. The results indicated that the Nuplazid treatment significantly suppressed tumour growth compared with the vehicle-treated group (Fig. 6a, b). Moreover, tumour weight was significantly decreased in the Nuplazid $44 \mathrm{mg} / \mathrm{kg}$ treatment group compared with the vehicletreated group (Fig. 6c). Meanwhile, the results indicated that although the tumour in the vehicle-treated group grew rapidly, Nuplazid reduced the growth of most tumours (Fig. $6 \mathrm{~d}$ ). Next the 
effect of Nuplazid on the expression of Ki67 was investigated by $\mathrm{IHC}$, and the results indicated that the Nuplazid treatment significantly inhibited the expression of Ki67 in tissues compared with the vehicle-treated group (Fig. 6e). The effect of Nuplazid on the PAK4 signaling pathway in tumour tissues was examined, and the results indicated that the Nuplazid treatment strongly suppressed the phosphorylation of MAPK1 in LEG110 tumours (Fig. 6f).

\section{DISCUSSION}

Esophageal cancer is one of the most common malignant tumours, with an estimated 572,000 new cases and 509,000 deaths annually [20]. Despite recent advances in treatments, patient prognosis remains poor [21-23]. Therefore, it is urgent to identify effective agents for ESCC prevention or recurrence prevention [24].

Drug repurposing has the potential to overcome several challenges associated with de novo drug discovery and guarantees quick clinical trials due to the already-established pharmacokinetics, tolerability, safety, and toxicity profile of the drug. Therefore, screening the FDA-approved drug library to select lowtoxicity and high-efficiency drugs for cancer prevention or recurrence prevention is extremely attractive. Through this strategy we discovered that Nuplazid was cytotoxic against ESCC cells and that it suppressed ESCC proliferation and clone formation in vitro. Nuplazid is an effective $5-\mathrm{HT} 2 \mathrm{~A}$ receptor inverse agonist that is clinically used to treat Parkinson's disease psychosis [25]. Recently, a study reported that Nuplazid exerts anticancer effects in pancreatic cancer cells [26]. However, the molecular targets and the inhibitory mechanism of Nuplazid remain to be elucidated.

Here, by analyzing phosphoproteome data after Nuplazid treatment and predicting the upstream kinase of the protein mapped to the signal pathway, we found that the activity of PAK4 changed significantly. Moreover, Swiss target analysis indicated that Nuplazid binds with PAK4. Interestingly, the binding assays and in vitro kinase assay provided strong evidence that Nuplazid targeted PAK4 and inhibited its activity. Interestingly, we found that MAPK1 can be phosphorylated by PAK4 at Y187, which was proved by in vitro kinase assay. MAPK $1^{\text {Y187 }}$ levels can be suppressed by Nuplazid treatment. All together, the PAK4 signaling pathway in ESCC cells was inhibited after Nuplazid treatment.

Accumulated evidence supports a critical role for abnormal PAK4 expression in oncogenesis, and amplification or activation of PAK4 has been detected in numerous cancers [27-29], including pancreatic, breast, and ovarian cancers [30]. Recent studies have indicated that PAK4 is associated with the risk of ESCC, and TCGA database analysis indicated that PAK4 expression in ESCC tissues was higher than in normal tissues [31]. We found that knockdown of PAK4 significantly suppressed the growth of ESCC cells, and knockdown of PAK4 led to ESCC cell resistance to Nuplazid. These multiple pieces of evidence indicated that PAK4 is a promising target of ESCC.

Fluorouracil, capecitabine, oxaliplatin and paclitaxel are often used in combination as chemotherapeutic agents for ESCC [32-36]. However, these drugs have side effects on the patient's physical and mental state, and the gradual development of drug resistance is also a challenge for clinical treatment [37]. Recently, studies have reported that some PAK4 molecular inhibitors, LCH-7749944 [15], FRAX1036 [38], and GNE 2861 [39], showed inhibitory effects in melanoma cells, colon cancer cells, breast cancer cells, and gastric cancer cells. However, these PAK4 inhibitors are still in preclinical research. Thus, a new PAK4 inhibitor that is not inferior in efficacy but that is favourable in toxicity is urgently needed. Nuplazid is a clinical drug already approved by the FDA with established safety data. Importantly, in the in vivo experiment, we proved that Nuplazid significantly suppressed tumour growth in mice PDXs at its clinical dose, which paved its way for further clinical trials.

In conclusion, our findings support the idea that Nuplazid is a potent PAK4 inhibitor, and could be used in ESCC chemoprevention.

\section{DATA AVAILABILITY}

The data supporting the findings of this study can be found in the article, Supplementary Information or available from the corresponding author upon reasonable request.

\section{REFERENCES}

1. Sung H, Ferlay J, Siegel RL, Laversanne M, Soerjomataram I, Jemal A, et al. Global cancer statistics 2020: GLOBOCAN estimates of incidence and mortality worldwide for 36 cancers in 185 countries. CA Cancer J Clin. 2021;71:209-49.

2. Abnet CC, Arnold M, Wei WQ. Epidemiology of esophageal squamous cell carcinoma. Gastroenterology. 2018;154:360-73.

3. Yan MH, Hou XB, Cai BN, Qu BL, Dai XK, Liu F. Neoadjuvant chemoradiotherapy plus surgery in the treatment of potentially resectable thoracic esophageal squamous cell carcinoma. World J Clin Cases. 2020;8:6315-21.

4. Ajani JA, D'Amico TA, Bentrem DJ, Chao J, Corvera C, Das P, et al. Esophageal and esophagogastric junction cancers, version 2.2019, NCCN Clinical Practice Guidelines in Oncology. J Natl Compr Canc Netw. 2019;17:855-83.

5. Al-Batran SE, Homann N, Pauligk C, Goetze TO, Meiler J, Kasper S, et al. Perioperative chemotherapy with fluorouracil plus leucovorin, oxaliplatin, and docetaxel versus fluorouracil or capecitabine plus cisplatin and epirubicin for locally advanced, resectable gastric or gastro-oesophageal junction adenocarcinoma (FLOT4): a randomised, phase 2/3 trial. Lancet. 2019;393:1948-57.

6. Shapiro J, Van Lanschot JJB, Hulshof MCCM, van Hagen P, Henegouwen MIV, Wijnhoven BPL, et al. Neoadjuvant chemoradiotherapy plus surgery versus surgery alone for oesophageal or junctional cancer (CROSS): long-term results of a randomised controlled trial. Lancet Oncol. 2015;16:1090-8.

7. Pushpakom S, lorio F, Eyers PA, Escott KJ, Hopper S, Wells A, et al. Drug repurposing: progress, challenges and recommendations. Nat Rev Drug Discov. 2019;18:41-58.

8. Parvathaneni V, Kulkarni NS, Muth A, Gupta V. Drug repurposing: a promising tool to accelerate the drug discovery process. Drug Discov Today. 2019;24:2076-85.

9. Bokoch GM. Biology of the p21-activated kinases. Annu Rev Biochem. 2003; 72:743-81.

10. Park S, Kim JW, Kim H, Kim JW, Kim YJ, Lee KW, et al. Prognostic value of p21activated kinase 4 in resected pancreatic cancer. APMIS. 2017;125:699-707.

11. Minden A. The pak4 protein kinase in breast cancer. ISRN Oncol. 2012;2012: 694201.

12. Wong LE, Chen N, Karantza V, Minden A. The Pak4 protein kinase is required for oncogenic transformation of MDA-MB-231 breast cancer cells. Oncogenesis. 2013;2:e50.

13. Siu MK, Chan HY, Kong DS, Wong ES, Wong OG, Ngan HY, et al. p21-activated kinase 4 regulates ovarian cancer cell proliferation, migration, and invasion and contributes to poor prognosis in patients. Proc Natl Acad Sci USA. 2010;107:18622-7.

14. Kobayashi $K$, Inokuchi $M$, Takagi $Y$, Otsuki $S$, Fujimori $Y$, Sato $Y$, et al. Prognostic significance of PAK4 expression in gastric cancer. J Clin Pathol. 2016; 69:580-5.

15. Zhang J, Wang J, Guo Q, Wang Y, Zhou Y, Peng H, et al. LCH-7749944, a novel and potent p21-activated kinase 4 inhibitor, suppresses proliferation and invasion in human gastric cancer cells. Cancer Lett. 2012;317:24-32.

16. Meltzer HY, Mills R, Revell S, Williams H, Johnson A, Bahr D, et al. Pimavanserin, a serotonin(2A) receptor inverse agonist, for the treatment of parkinson's disease psychosis. Neuropsychopharmacology. 2010;35:881-92.

17. Shen ZY, Xu LY, Chen XH, Cai WJ, Shen J, Chen JY, et al. The genetic events of HPV-immortalized esophageal epithelium cells. Int J Mol Med. 2001;8:537-42.

18. Zhao S, Jiang $Y$, Zhao J, Li H, Yin X, Wang $Y$, et al. Quercetin-3-methyl ether inhibits esophageal carcinogenesis by targeting the AKT/mTOR/p70S6K and MAPK pathways. Mol Carcinog. 2018;57:1540-52.

19. Xie Y, Dong CD, Wu Q, Jiang Y, Yao K, Zhang J, et al. Ornithine decarboxylase inhibition downregulates multiple pathways involved in the formation of precancerous lesions of esophageal squamous cell cancer. Mol Carcinog. 2020;59: 215-26.

20. Siegel RL, Miller KD, Jemal A. Cancer statistics, 2018. CA Cancer J Clin. 2018; 68:7-30. 
21. Gao J, Wang Y, Yang J, Zhang WX, Meng K, Sun Y, et al. RNF128 Promotes invasion and metastasis via the EGFR/MAPK/MMP-2 pathway in esophageal squamous cell carcinoma. Cancers. 2019;11:840.

22. Lin DC, Wang MR, Koeffler HP. Genomic and epigenomic aberrations in esophageal squamous cell carcinoma and implications for patients. Gastroenterology. 2018;154: 374-89.

23. Harirchi I, Kolahdoozan S, Hajizadeh S, Safari F, Sedighi Z, Nahvijou A, et al. Esophageal cancer in Iran; a population-based study regarding adequacy of cancer surgery and overall survival. Eur J Surg Oncol. 2014;40:352-7.

24. Ilson DH. Esophageal cancer chemotherapy: recent advances. Gastrointest Cancer Res. 2008:2:85-92.

25. Snigdha S, Horiguchi M, Huang M, Li Z, Shahid M, Neill JC, et al. Attenuation of phencyclidine-induced object recognition deficits by the combination of atypical antipsychotic drugs and pimavanserin (ACP 103), a 5-hydroxytryptamine(2A) receptor inverse agonist. J Pharmacol Exp Ther. 2010;332:622-31.

26. Ramachandran S, Srivastava SK. Repurposing pimavanserin, an anti-Parkinson drug for pancreatic cancer therapy. Mol Ther Oncolytics. 2020;19:19-32.

27. Huynh N, Wang K, Yim M, Dumesny CJ, Sandrin MS, Baldwin GS, et al. Depletion of p21-activated kinase 1 up-regulates the immune system of APC(Delta 14/+) mice and inhibits intestinal tumorigenesis. BMC Cancer. 2017;17:431.

28. Minden A. PAK4-6 in cancer and neuronal development. Cell Logist. 2012;2: 95-104.

29. Kumar R, Li DQ. PAKs in human cancer progression: from inception to cancer therapeutic to future oncobiology. Adv Cancer Res. 2016;130:137-209.

30. Rane CK, Minden A. P21 activated kinase signaling in cancer. Semin Cancer Biol. 2019;54:40-49.

31. Huang $H$, Xue Q, Du X, Cui J, Wang J, Cheng D, et al. p21-activated kinase 4 promotes the progression of esophageal squamous cell carcinoma by targeting LASP1. Mol Carcinog. 2020;60:38-50.

32. Xu Z, Hu C, Chen S, Zhang C, Yu J, Wang X, et al. Apatinib enhances chemosensitivity of gastric cancer to paclitaxel and 5-fluorouracil. Cancer Manag Res. 2019;11:4905-15.

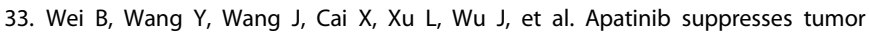
progression and enhances cisplatin sensitivity in esophageal cancer via the Akt/ beta-catenin pathway. Cancer Cell Int. 2020;20:198.

34. Zhang P, Feng FY, Wu LY, Hu Y, Liu JW, Gao YJ, et al. [Phase II multicenter clinical trial of nedaplatin in the treatment of malignant tumors]. Zhonghua Zhong Liu Za Zhi. 2006;28:230-4.

35. Qiu H, Li J, Liu Q, Tang M, Wang Y. Apatinib, a novel tyrosine kinase inhibitor, suppresses tumor growth in cervical cancer and synergizes with Paclitaxel. Cell Cycle. 2018;17:1235-44.

36. Yang LY, Cheng ZJ, Liu Z, Wang D, Zhang N, Fan ZL, et al. Remarkable inhibition effects of afatinib alone or combining with paclitaxel in esophageal squamous cell carcinoma. J Gastroenterol Hepatol. 2021;36:2513-22.

37. Chen Y, Ye J, Zhu Z, Zhao W, Zhou J, Wu C, et al. Comparing paclitaxel plus fluorouracil versus cisplatin plus fluorouracil in chemoradiotherapy for locally advanced esophageal squamous cell cancer: a randomized, multicenter, phase III clinical trial. J Clin Oncol. 2019;37:1695-703.

38. Ong CC, Gierke S, Pitt C, Sagolla M, Cheng CK, Zhou W, et al. Small molecule inhibition of group I p21-activated kinases in breast cancer induces apoptosis and potentiates the activity of microtubule stabilizing agents. Breast Cancer Res. 2015;17:59.

39. Karpov AS, Amiri P, Bellamacina C, Bellance MH, Breitenstein W, Daniel D, et al. Optimization of a dibenzodiazepine hit to a potent and selective allosteric PAK1 inhibitor. ACS Med Chem Lett. 2015;6:776-81.

\section{AUTHOR CONTRIBUTIONS}

$\mathrm{KL}$ and $\mathrm{JZ}$ planned experiments and revised the paper. $\mathrm{YW}$ wrote the paper and performed experiments. YJ supervised and directed the experiment. WW and $\mathrm{HZ}$ analysed research data. LZ, XW, QY and LH contributed reagents or other essential material. All authors contributed to the article and approved the submitted version.

\section{FUNDING}

This research was supported by National Natural Science Foundations of China (grant number 81872335), the National Science \& Technology Major Project Key New Drug Creation and Manufacturing Program, China (No. 2018ZX09711002), National Natural Science Youth Foundation (grant number 81902486), the Natural Science Foundation of Henan (grant number 161100510300), the Science and Technology Project of Henan Province (grant number 212102310187).

\section{COMPETING INTERESTS}

The authors declare no competing interests.

\section{ETHICS APPROVAL AND CONSENT TO PARTICIPATE}

All animal experiments and clinical samples were performed following the Declaration of Helsinki and approved by the Zhengzhou University Ethics Committee (Zhengzhou, Henan, China) and Consent as obtained for all cancer tissues utilised in the study from the cancer patients.

\section{CONSENT FOR PUBLICATION}

Written informed consent was provided by all patients for the use of the tissue samples.

\section{ADDITIONAL INFORMATION}

Supplementary information The online version contains supplementary material available at https://doi.org/10.1038/s41416-021-01651-z.

Correspondence and requests for materials should be addressed to Jimin Zhao or Kangdong Liu.

Reprints and permission information is available at http://www.nature.com/ reprints

Publisher's note Springer Nature remains neutral with regard to jurisdictional claims in published maps and institutional affiliations.

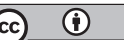

Open Access This article is licensed under a Creative Commons Attribution 4.0 International License, which permits use, sharing, adaptation, distribution and reproduction in any medium or format, as long as you give appropriate credit to the original author(s) and the source, provide a link to the Creative Commons license, and indicate if changes were made. The images or other third party material in this article are included in the article's Creative Commons license, unless indicated otherwise in a credit line to the material. If material is not included in the article's Creative Commons license and your intended use is not permitted by statutory regulation or exceeds the permitted use, you will need to obtain permission directly from the copyright holder. To view a copy of this license, visit http://creativecommons. org/licenses/by/4.0/.

(c) The Author(s) 2021 